04

\title{
Голографические волноводные перископы в дисплеях дополненной реальности
}

\author{
(C) А.Н. Путилин ${ }^{1}$, А.В. Морозов ${ }^{1,2}$, С.С. Копенкин ${ }^{1}$, С.Е. Дубынин ${ }^{1,2}$, Ю.П. Бородин ${ }^{1}$ \\ ${ }^{1}$ Физический институт им. П.Н. Лебедева РАН, \\ 119991 Москва, Россия \\ ${ }^{2}$ Исследовательский центр Самсунг в Москве, \\ 127018 Москва, Россия \\ e-mail: putilinan@lebedev.ru
}

Поступила в редакцию 15.03.2020 г.

В окончательной редакции 16.06.2020 г.

Принята к публикации 07.07.2020 г.

Рассмотрены основные свойства голографических волноводных перископических мультиплексоров выходного зрачка оптических систем дисплеев дополненной реальности. Приведены анализ ограничений в работе волноводных голограмм, компенсации хроматизма в перископических схемах и влияние дефектов волноводов на работу дисплеев дополненной реальности построенных на базе волноводных голограмм.

Ключевые слова: голографические оптические элементы, дисплеи дополненной реальности, волноводные голограммы.

DOI: $10.21883 /$ OS.2020.11.50172.93-20

\section{Введение}

Виртуализация пространства, окружающего современного человека, идет быстрыми темпами, поскольку цифровые технологии занимают все больший сектор информационного потока. Оптический канал информации - самый емкий для человеческого восприятия, соответственно создание виртуальных (Virtual Reality VR) дисплеев, а более правильно дисплеев дополненной (Augmented Reality - AR) реальности, становится очень актуальной задачей. Отличительной их чертой является формирование мнимого (виртуального) увеличенного изображения локального источника информации и высокая прозрачность для света от реальной окружающей зрителя обстановки.

По способу взаимодействия со зрителем AR-дисплеи можно разделить на два больших класса: Head-up (HUD)-дисплеи или дисплеи перед зрителем (жестко связаны с устройством, используемым человеком, машина, самолет и пр.) и Head-mounted (HMD), или „носимые на голове“ дисплеи (связанные достаточно гибко со зрительным аппаратом человека); обобщенные схемы таких дисплеев приведены на рис. 1. Основные параметры оптических схем таких дисплеев сильно различаются: HUD характеризуются жесткой связью ARдисплея с носителем (самолет, машина), огромным выносом зрачка (Eye relief, ER - расстояние от последнего оптического элемента AR-дисплея до зрителя) 80-1000 mm, зрачком (Eye box, EB) для рассматривания двумя глазами $(>100 \times 30 \mathrm{~mm})$, полем зрения (field of view, FOV) $<30^{\circ}$. Высокая надежность таких дисплеев требуется для обеспечения безопасности зрителя. Для HMD характерна нежесткая связь AR-дисплея с носителем (очки, шлем), небольшой вынос зрачка $\mathrm{ER}=20-30 \mathrm{~mm}$, зрачок $\mathrm{EB} \sim 5-15 \mathrm{~mm}$, поле зрения FOV $>45^{\circ}$, небольшой вес $(<150 \mathrm{~g})$. Оптические схемы таких разных по параметрам устройств имеют особенные черты, но общая тенденция в создании ARдисплеев - это минимизация адаптации зрителя под оптимальные условия видения виртуальных изображений (отсутствие индивидуальной настройки). Одним из самых критичных параметров таких дисплеев является выходной зрачок системы (EB): для HMD желательно значение этого параметра не меньше 10-12 mm, а для HUD - не менее $100 \mathrm{~mm}$, что связано с необходимостью обеспечения свободного перемещения зрителя относительно AR-дисплея и высокой подвижностью зрачка человека при рассматривании широкоапертурных виртуальных изображений (больше $25-30^{\circ}$ ). Необходимость синтеза большого выходного зрачка для систем отображения мнимого увеличенного изображения, используемых в HMD- и HUD-дисплеях, оказались очень плодотворной для развития волноводной голографии. Использование волноводных голограмм для этих целей было целью многих работ еще в 80-е годы 20 века [1-3], однако только теперь их применение дошло до реальных устройств.

\section{Волноводные голограммы}

B оптических схемах AR дисплеев голографические оптические элементы используются довольно широко в качестве устройств совмещения световых потоков, осветителей, изображающих линз, селективных фильтров [4], но в этой работе мы сосредоточим внимание на описании работы и ограничениях в использовании 
$a$

HUD

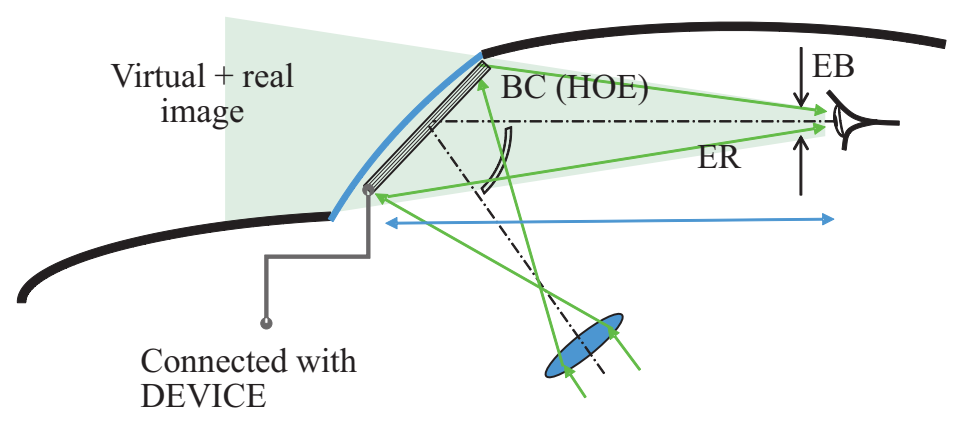

$b$

Connected with viewer

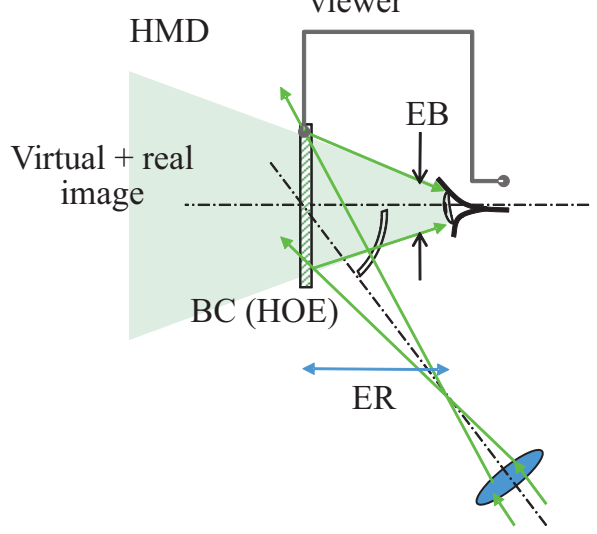

Рис. 1. Различия оптических схем HUD и HMD. BC (beam-combiner) - элемент совмещения световых потоков, НOE (holographic optical element) - голографический элемент совмещения световых потоков. (a) HUD - жесткая связь AR-дисплея с носителем (самолет, машина), огромный вынос зрачка - Eye relief(ER) (расстояние от последнего оптического элемента AR-дисплея до зрителя) 80-1000 mm, зрачок - Eye box (EB) для рассматривания двумя глазами $(>100 \times 30 \mathrm{~mm})$, поле зрения FOV $<30^{\circ}$. Высокая надежность. (b) HMD - не жесткая связь AR-дисплея с носителем (очки, шлем), небольшой вынос зрачка $\mathrm{ER}=20-30 \mathrm{~mm}$, зрачок $\mathrm{EB} \sim 5-15 \mathrm{~mm}$, поле зрения $\mathrm{FOV}>45^{\circ}$, небольшой вес $(<150 \mathrm{~g})$.

голограмм на полном внутреннем отражении, в частности, волноводных голограмм, как базовых элементов не изображающих перископических систем дисплеев дополненной реальности, важной целью которых является синтез большого выходного зрачка AR-дисплея и, конечно, роль элемента совмещения световых потоков.

Волноводные голограммы - это вид голограмм, при записи или реконструкции которых используется излучение, распространяющееся по волноводу, оптическому волокну или внутри оптических элементов благодаря полному внутреннему отражению [5]. Работы в этой области активно развиваются с 1970-х годов, несколько волн интереса к волноводным голограммам были вызваны рядом выдающихся их свойств: высокой дифракционной эффективности - свыше 90\%, полному разделению изображающих и не дифрагированных на голограмме пучков, пространственно-временным преобразованиям информации, недоступным обычной оптике и голографии и, наконец, совместимости с массовой интегральной технологией.

И на самом деле, наиболее широко распространившееся в настоящее время HMD - Hololens, Magic Leap, Aconia, Digilens, BAE systems построены именно на голографических перископических базовых элементах (рис. 2) [6]. Отличительной особенностью этих устройств являются планарность, компактность, легкий вес и компенсированный хроматизм в голографическом перископе.

Базовой схемой записи волноводных голограмм, выполняющих роль устройств связи, т.е. выполняющих роль преобразователя волноводных мод в моды свободного пространства, можно считать схему рис. 3.
В отличие от записи обычных голограмм Лейта-Упатниекса схема записи волноводных голограмм должна позволять возбуждать в оптической регистрирующей среде (РС) лучи, соответствующие модам волновода. Это достигается либо использованием специальных устройств связи - призм (как в нашем случае), либо использованием при записи таких голограмм иной, чем при воспроизведении длины волны, но тогда возникают значительные аберрации, либо реальным возбуждением волноводных мод, но это, как правило, вызывает дополнительные шумы и искажения в записанной волноводной голограмме. Как показано на рис. $3, b$, при записи волноводной голограммы реально записываются несколько интерференционных картин, которые при воспроизведении часто приводят к шумам, искажениям или уменьшению дифракционной эффективности голограмм. В большинстве конкретных случаев эти искажения можно минимизировать. Другой важной особенностью волноводных голограмм является повышенные требования к свойствам регистрирующей среды: для голографии больше подходят фазовые среды с очень низким поглощением и светорассеянием, в наших экспериментах мы используем PC Bayfol фирмы Covestro (бывшая Bayer MS) и, когда возможно, фоторезистивные слои с переносом рельефа на волновод при помощи фотополимеризующихся композиций. Запись нескольких голограмм на одном волноводе формирует базовый элемент волноводного голографического перископа.

Рассмотрим схему работы такого перископа (рис. 4): вводная решетка WGH1 преобразует объемную волну в волноводную моду, при этом угол падения $\beta$, угол волноводной моды $\alpha$, показатель преломления волновода $n$ и период решетки $d$ связаны условиями волноводной 

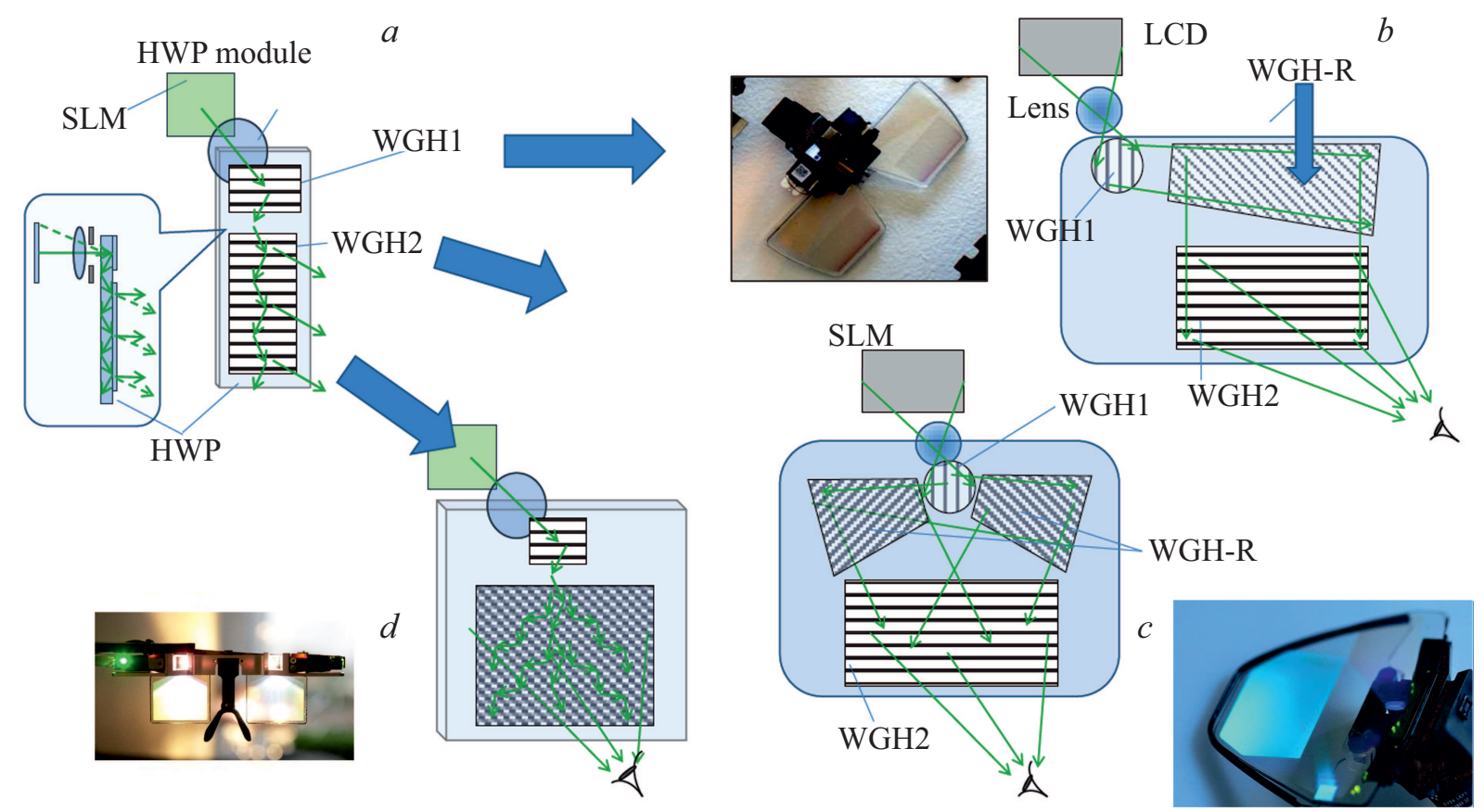

Рис. 2. HWP (holographic waveguide periscope) — голографический волноводный перископ, WGH1 - вводная волноводная голограмма, WGH2 - выводная волноводная голограмма, WGH-R - волноводная голограмма редиректор, $L$ - проекционная оптика, SLM - модулятор локального источника информации. (a) Базовый модуль не изображающего перископа, $(b)$ трехголограммная схема Microsoft HoloLens (Nokia Research), (c) Hololens 2 с увеличенным FOV, (d) HMD WaveOptics - с комбинированным голографическим размножителем зрачка - WGH2.

дифракции света длины волны $\lambda$ :

$$
n \sin \alpha-\sin \beta=m \frac{\lambda}{d}
$$

В данном случае имеет смысл учитывать только первые порядки дифракции $(m= \pm 1)$, поскольку для актуальных углов дифракции вторые и высшие порядки уже отсутствуют, что положительно сказывается на эффективности решеток и уменьшении шума в системе. Свет, не дифрагировавший на решетке, проходит волноводную структуру насквозь и покидает оптическую систему. Выводная решетка WGH2 выполняет обратную функцию вывода излучения из волновода, но поскольку недифрагироваший свет из волновода выйти не может, то после многократного отражения в волноводе в выходящем из волновода излучении наблюдаются множество лучей - близнецов падающего пучка, с распределением интенсивности, зависящим от локального распределения дифракционной эффективности (ДЭ) голограммы WGH2 [7] и с пространственным смещением вдоль направления распространения света в волноводе.

При одинаковой ДЭ $\eta$ по площади голограммы интенсивность каждого следующего выходящего пучка ниже интенсивности предыдущего:

$$
I_{k}=\eta(1-\eta)^{k-1}
$$

Для получения равномерного выходящего излучения необходимо обеспечить увеличение ДЭ от каждого по- следующего отражения в волноводе по закону:

$$
\eta_{n}=\frac{\eta_{n-1}}{1-\eta_{n-1}}
$$

Но это требует записи волноводных голограмм с неоднородно увеличивающейся ДЭ, и то только в пределах максимально возможной ДЭ конкретной регистрирующей среды.

Поскольку хроматическая дисперсия обеих голографических решеток одинакова, то в результате двукратной дифракции происходит компенсация углов дифракции для разных длин волн. На рис. 4, а показаны углы дифракции для достаточно хорошего охвата цветового треугольника RGB. Видно, что хроматизм волноводных голограмм очень велик, соответственно при некомпенсированном воспроизведении волноводной голограммы построение четкого изображение невозможно для нелазерного источника.

Для каждой цветовой компоненты RGB-засветки существуют свои периоды расположения точек возврата (постоянная распространения мод волновода) при многократном взаимодействии голограммы с волноводной модой, максимальный период всегда у наибольшей длины волны, что приводит к окрашиванию выводимого из волновода изображения: дальний от входной голограммы край изображения более красный (рис. $4, b)$, а ближний, наоборот, синий (рис. 4,c). Интересный эффект самосогласованного RGB-воспроизведения волноводных голограмм был описан в [8]: после определенного количе- 


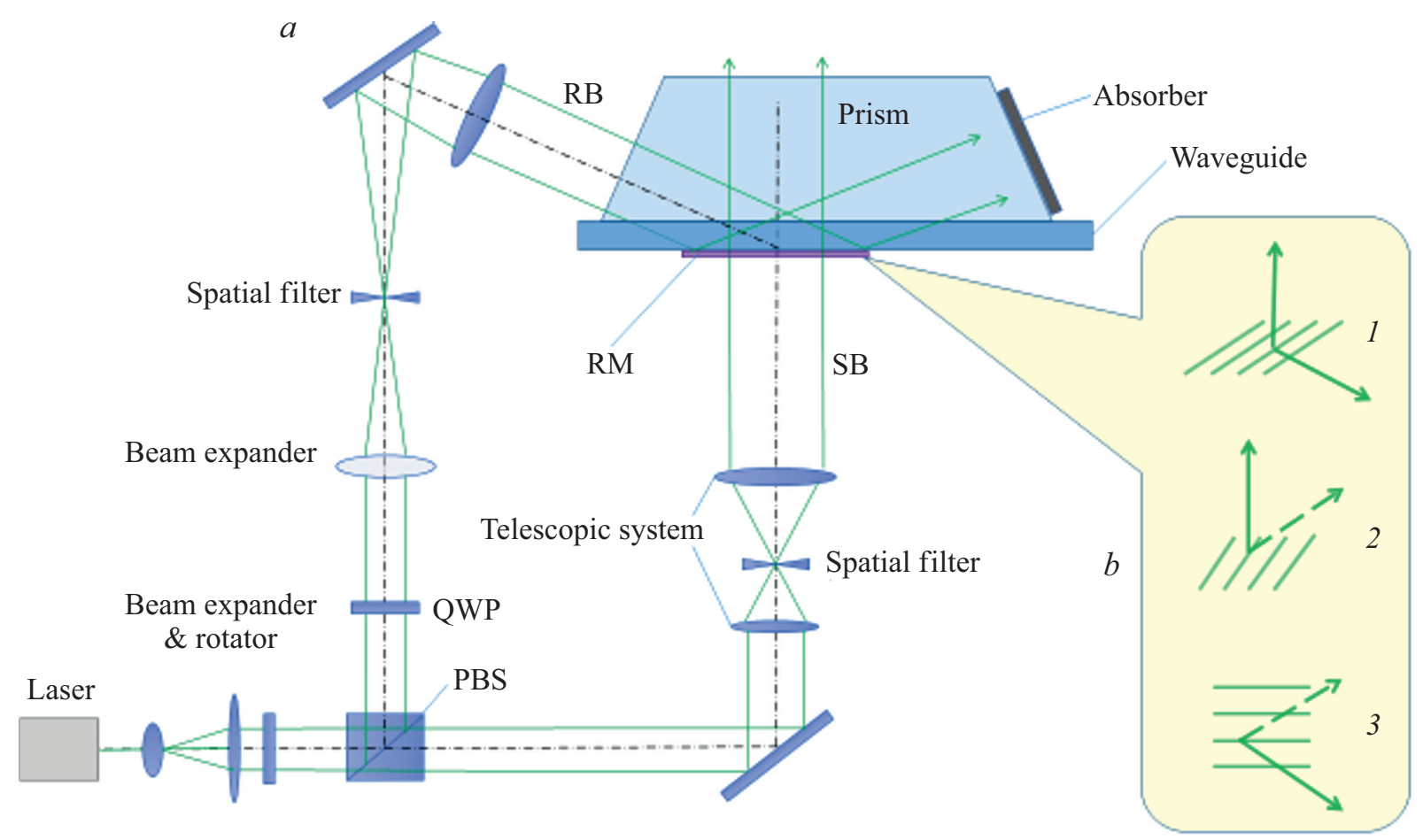

Рис. 3. Схема записи волноводных голограмм „на зоне связи“ призма-волновод. (a) RB - опорный пучок, SB - предметный пучок, RM - голографическая регистрирующая среда, PBS - поляризационный делительный кубик, QWP - четвертьволновая пластина. На выноске $(b)$ показан вид интерференционных картин, которые одновременно записываются на волноводной голограмме: 1 - интерференционная картина, образованная падающими опорным и предметным пучками, $2-$ интерференционная картина, образованная отраженным от границы раздела сред опорным и предметным пучками, 3 - интерференционная картина, образованная падающими опорным и отраженным от границы раздела сред опорным пучками.

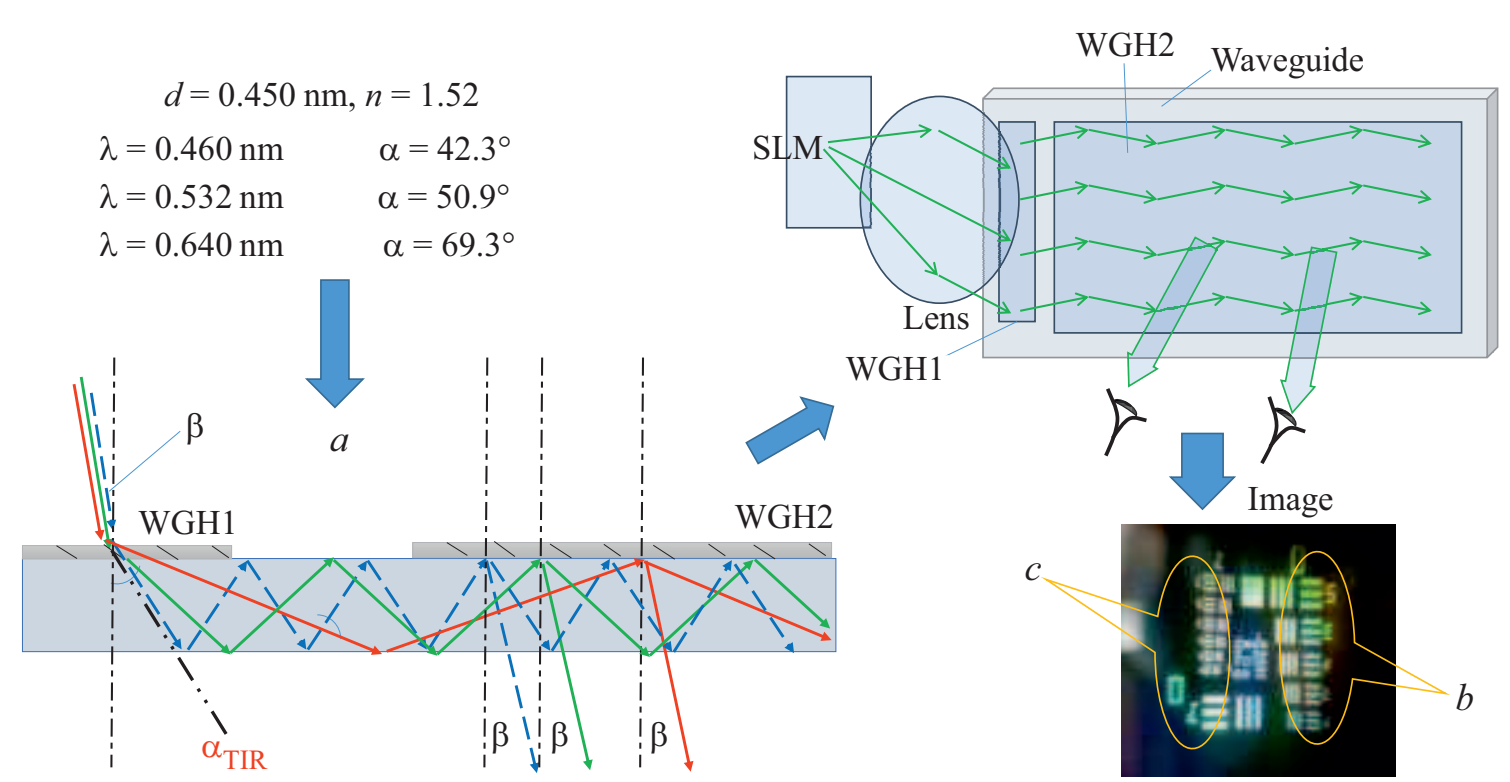

Рис. 4. Схема работы голографического волноводного перископа с полихроматической засветкой. (a) Работа согласованной пары голограмм. $(b)$ окрашивание правого края голограммы в красноватые тон при формировании мнимого увеличенного изображения в белом некогерентном свете, $(c)$ окрашивание левого края в голубоватые тона - результат различия периодов точек возврата от длины волны, $(d)$ в изображенной схеме размер выводной голограммы и синтезированный ЕВ $200 \mathrm{~mm}$ для рассматривания виртуального изображения двумя глазами. 
ства переотражений в волноводе цветовые компоненты снова концентрировались в одной области волновода, в частности, при нормальном падении света на волновод, соотношение толщины волновода $-a$ и периода расположения точек возврата $-h$ равно

$$
\frac{h}{a}=\frac{\lambda}{\left((n d)^{2}-\lambda^{2}\right)^{1 / 2}} .
$$

В частном случае светодиодов с длинами волн 455 , 540 и $640 \mathrm{~nm}$ и при соотношении отражений приблизительно 2:4:6 для таких RGB-составляющих происходила достаточно хорошая хроматическая компенсация вывода некогерентного излучения из волновода как по углу дифракции, так и по положению точек вывода (рис. 5,a). Кроме того, в случае записи фокусирующих выводящих решеток (голографических линз) можно будет компенсировать, по крайней мере, частично и продольный хроматизм фокусировки, поскольку эквивалентное фокусное расстояние линзы для цветовых составляющих будет увеличиваться пропорционально оптическому пути цветовых составляющих (рис. 5, $b$ ).

Сейчас в большинстве схем HMD используется трехголограммная схема размножения зрачка (рис. $6, a, b$ ), позволяющая размножать зрачок до 10-15 mm по двум координатам, но обладающая значительным некомпенсированным голографическим хроматизмом на поворотном голографическим элементе WGH-R, преобразующем волноводную моду в волноводную же, но идущую в ортогональном направлении, поэтому для снижения влияния этого хроматизма используют раздельные RGBволноводы для каждой длины волны [6], лазерные источники света или светодиоды с узкополосными $(2-3 \mathrm{~nm})$ интерференционными фильтрами (рис. 6, c). Отрицательное влияние третьей голограммы проявляется еще и в том, что поле зрения таких схем имеет жесткое ограничение по двум координатам, это является следствием лимита диапазона углов распространения света в волноводных голографических перископах и изменения на ортогональное направления распространения мод волновода на этой поворотной голограмме. Указанные ограничения будут рассмотрены подробно в следующем разделе работы.

\section{Ограничения в работе волноводного голографического перископа}

Ограничение по угловой апертуре пропускаемого через волновод изображения в волноводных перископических схемах вытекает из оптического ограничения ПВО распространения света в волноводе, рассмотрим голографический перископ с этой точки зрения (рис. 7), наиболее жесткими ограничениями обладают волноводы в направлении вектора вводной голографической решетки, эти ограничения и рассмотрим сначала. Ограничения апертуры изображений в направлении, перпендикулярном вектору вводной решетки, также существуют, но они не такие жесткие и характерны для любой, а не только волноводной голограммы.

С одной стороны, есть ограничение собственно ПВО эффекта: $\alpha_{\mathrm{TIR}}=\arcsin (1 / n)-$ рис. 7 луч $a$, для волноводов из крон-стекол имеем угол полного внутреннего отражения порядка $41^{\circ}$, уменьшить этот угол можно за счет увеличения показателя преломления волновода до $1.6-1.7$, тогда $\alpha_{\mathrm{TIR}}$ уменьшится до $36-35^{\circ}$, однако и цена, и прозрачность для видимого диапазона длин волн таких стекол не всегда приемлемы. Другим ограничением диапазона направляемых мод являются скользящие углы $\alpha_{\max }$ на рис. 7. С одной стороны, такие лучи имеют очень большой пространственный период точек возврата при взаимодействии с волноводной голограммой, и поэтому в формируемом виртуальном изображении часто наблюдаются резкие изменения яркости изображения, полосы и затемнения, к тому же они быстро выходят из выходной апертуры HMD-дисплея. C другой стороны, они образуют максимальный угол взаимодействия с волноводной решеткой; ДЭ при таких углах может значительно уменьшиться, поэтому скользящий луч (рис. $6, b$ ) редко удается увеличить до $72-75^{\circ}$. Таким образом, даже при увеличении показателя преломления волновода до 1.7 общий диапазон углов $\Delta \alpha \sim \alpha_{\mathrm{TIR}}-\alpha_{\max }$ (т.е. апертура передаваемого через волновод изображения) не превышает $35-38^{\circ}$ в направлении вектора волноводных решеток. Одно из общих положений, верное для рефракционной оптики, состоит в том, что диапазон углов неплоского волнового фронта, например, при переходе из воздуха в стекло, уменьшается примерно пропорционально отношению показателей преломления граничащих сред, а для волноводной голографии в тех допущениях, что используются для волноводных голографических перископов, это не так: при вводе в волновод диапазон углов

$$
\frac{\Delta \alpha}{\Delta \beta}=\frac{\cos \beta}{\sqrt{1-\left(\frac{\sin \beta}{n}+\frac{\lambda}{n d}\right)^{2}}}
$$

в воздухе и в волноводе примерно одинаков. Например, при вводе зеленого $(0.532 \mathrm{~nm})$ излучения лазера и для углов ввода-вывода на голограмме близких к нормали в волновод с $n=1.52 \Delta \alpha / \Delta \beta=1.05$, а в волновод с $n=1.7$ уменьшается незначительно $-\Delta \alpha / \Delta \beta=0.94$.

Есть еще один фактор, жестко ограничивающий диапазон углов волноводных голографических перископов: это показатель преломления РС, используемой для записи волноводных голограмм, поскольку на границе раздела волновод - регистрирующая среда тоже будет отражаться волноводная мода, а если показатель преломления РС меньше такового волновода, то будет наблюдаться ПВО (рис. 6 , луч $d$ ), и луч $c$, будучи введенным в волновод, воспроизводить голограмму WGH2 не будет. Поскольку PC Bayfol и фотополимеры, на которые часто переносят рельеф при копировании голограмм, имеют показатели преломления не больше 1.53 , 


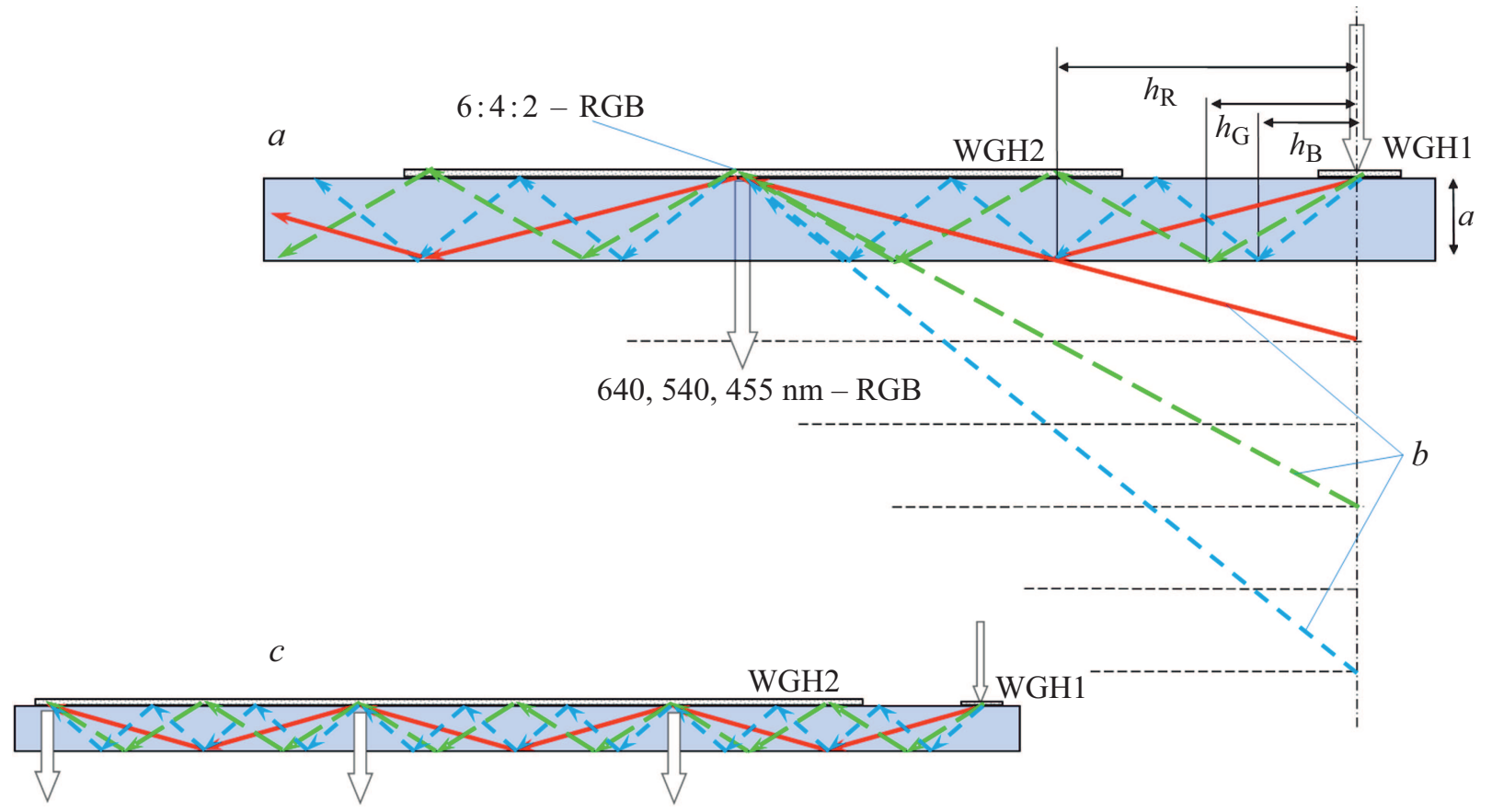

Рис. 5. Пространственно-самосогласованная ахроматизация воспроизведения волноводных голограмм. (a) Формирование области хорошей ахроматизации для определенного набора RGB-составляющих, $(b)$ оптические пути для отдельных цветовых компонент $\mathrm{RGB},(c)$ пространственно-самовоспроизводящаяся структура самосогласованной ахроматизации.

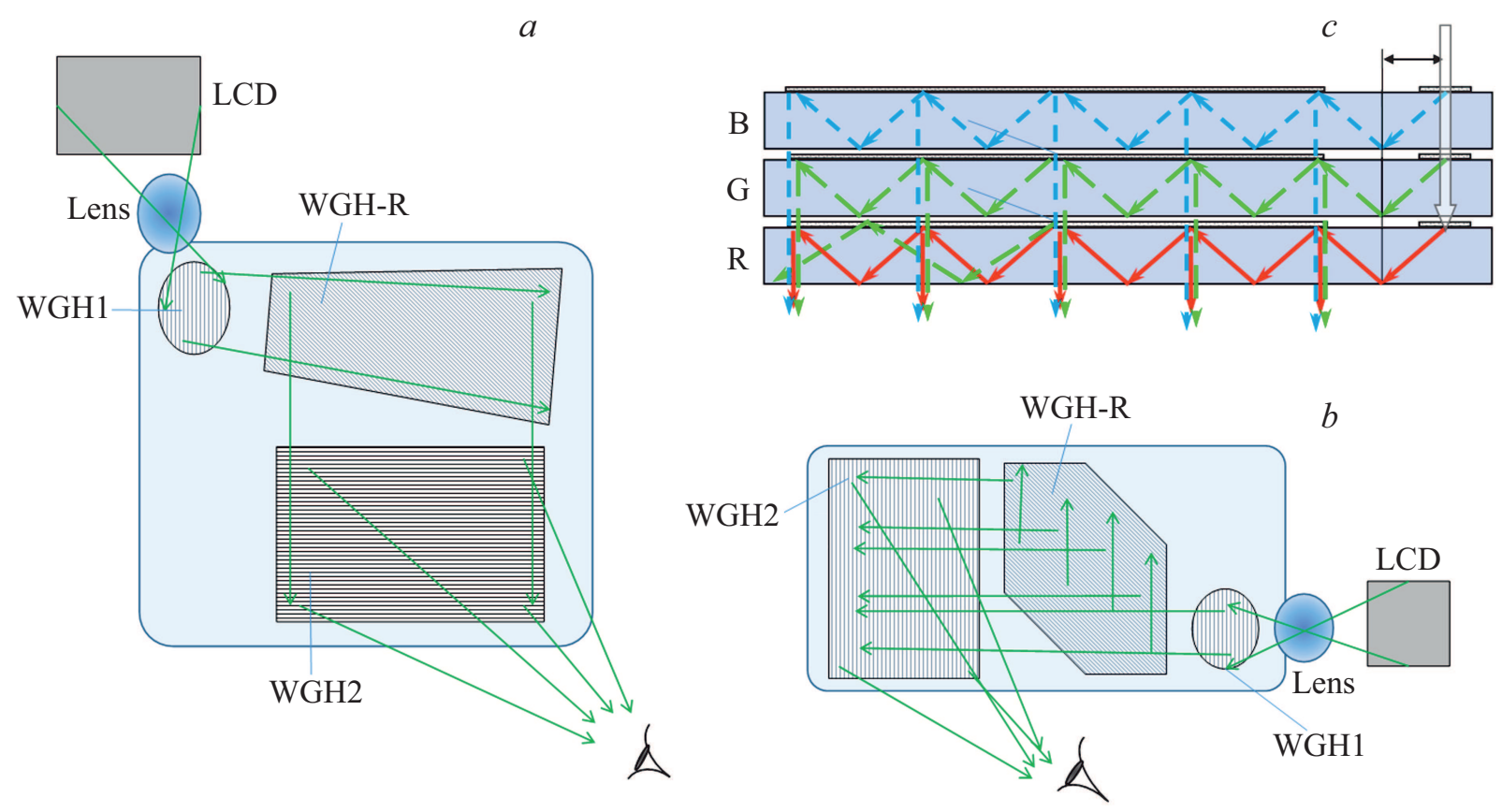

Рис. 6. Трехголограммная схема с неполной ахроматизацией формируемого виртуального изображения. (a) Hololens 1 - сначала происходит размножение зрачка на редиректоре WGH-R по горизонтали, а затем на WGH2 по вертикали, (b) схема работы Light trans с использование нулевого прядка дифракции на WGH-R, (c) для обеспечения оптимальной работы трехголограммных схем необходимо использование раздельных волноводов для каждой RGB-компоненты.

то скользящие углы даже для волноводов с $n=1.7$ не будут превышать $65^{\circ}$; отсюда вытекает одна из фундаментальных проблем волноводной голографии разработка регистрирующих сред с большим показате- лем преломления. Есть, конечно, халькогенидные стеклообразные полупроводники, но поглощение света для сине-зеленой области спектра делает невозможным их применение в полноцветных HMD-дисплеях. 


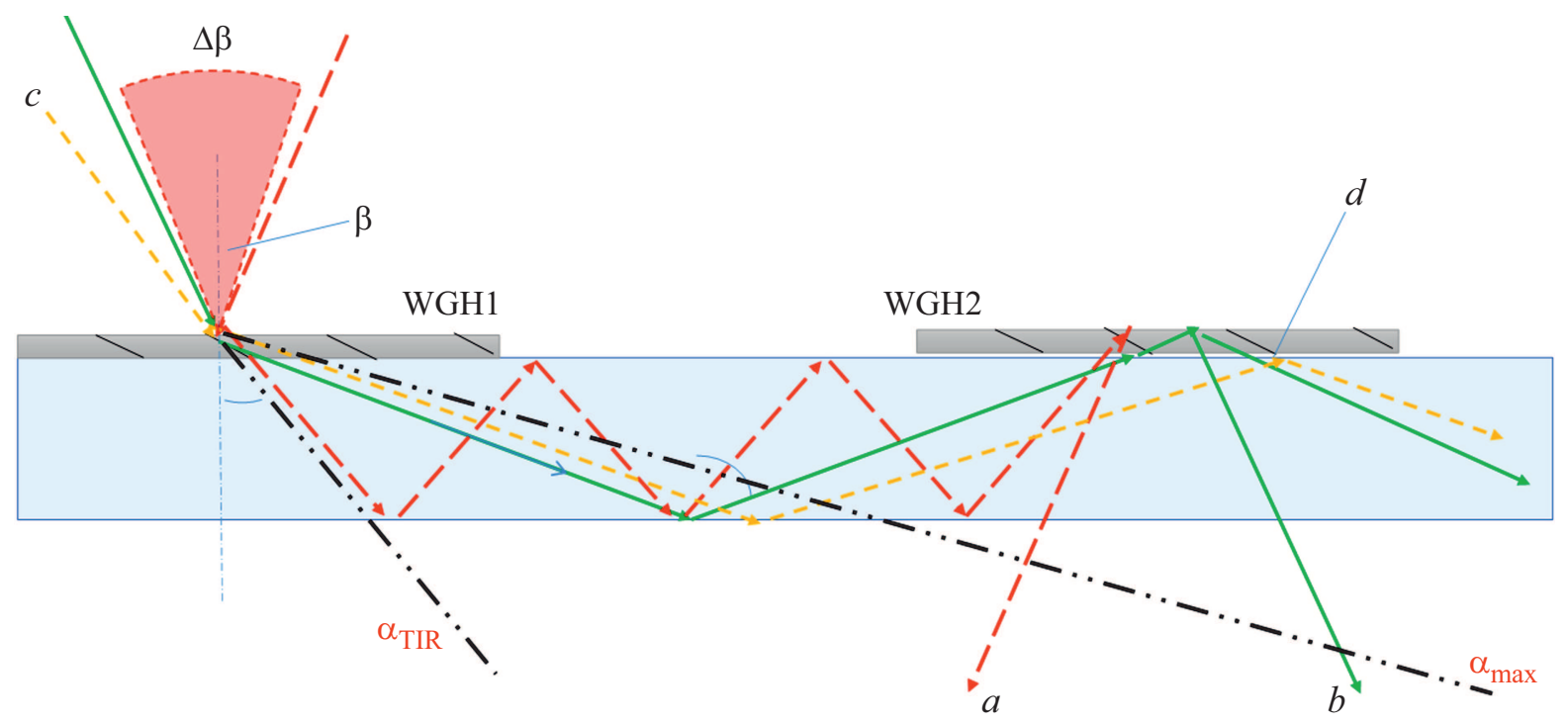

Рис. 7. Ограничение рабочей апертуры волноводных голографических перископов. (a) Ограничение лучей углом полного внутреннего отражения в волноводе $\alpha_{\mathrm{TIR}},(b)$ ограничение скользящих лучей, $(c)$ ограничение углов ввода полным внутренним отражением на границе волновод-регистрирующая среда $(d)$.

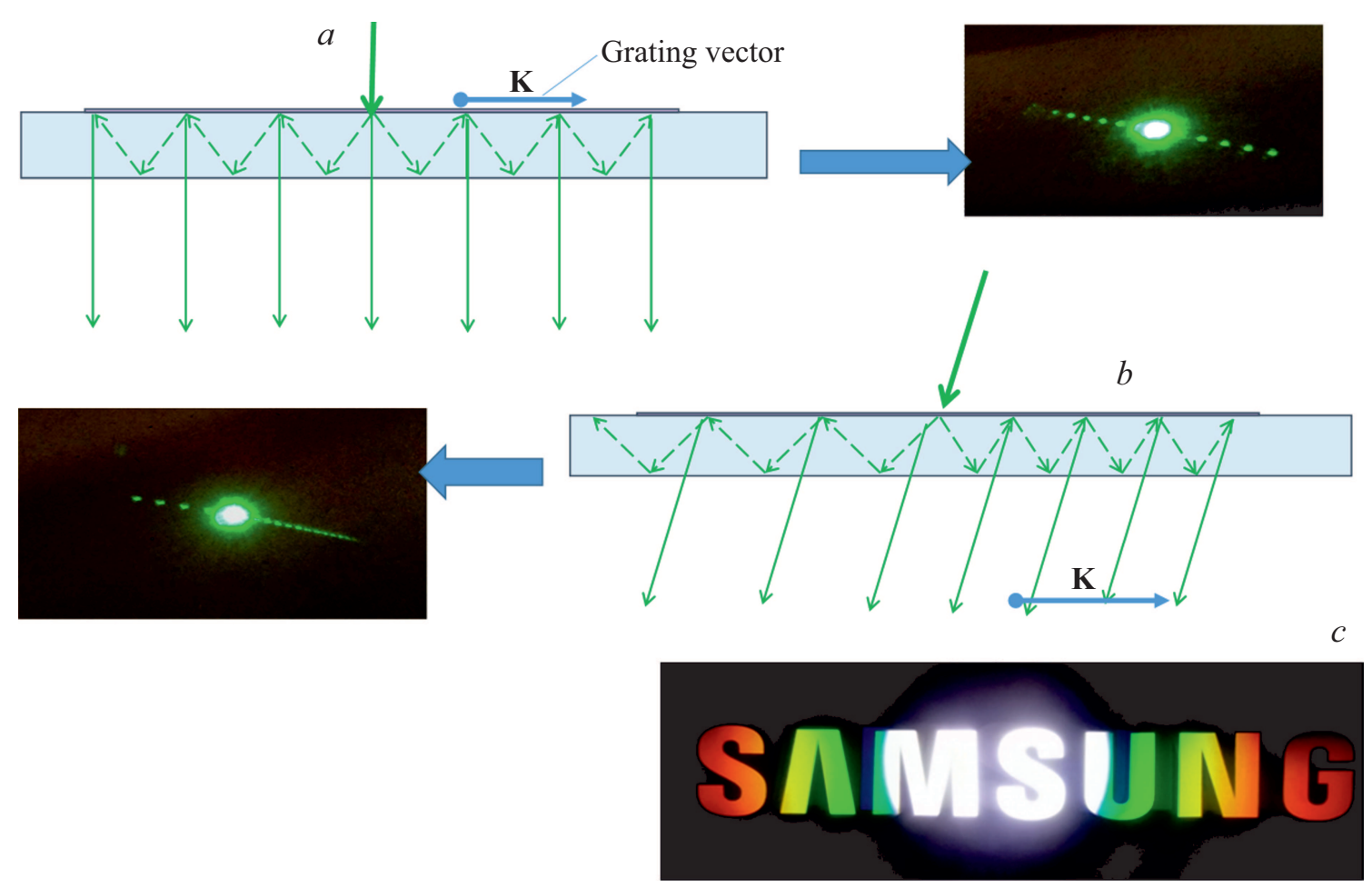

Рис. 8. Ввод разных порядков волноводной дифракции в разнонаправленное распространение мод волновода. (a) Симметричное возбуждение мод + и - первыми порядками дифракции, $(b)$ при изменении угла падения угол мод меняется, но выходящие лучи образуют параллельные лучи, т. е. происходит согласованное формирование единого виртуального изображения $(c)$.

Расширить апертуру вводимого в волновод изображения можно за счет балансного режима ввода, при котором часть изображения вводится преимущественно в первый порядок дифракции, а другая в минус первый (рис. 8). При изменении угла падения падающего луча меняется период точек возврата мод -1-го и +1-го по- рядков, но углы вывода синхронно изменяются, поэтому целостность восприятия виртуального изображения не меняется.

Именно таким образом работает вводная решетка в схеме Hololens2 pис. 2,c [6], хотя по сути в схеме нет никаких голографических линз: это голографический 


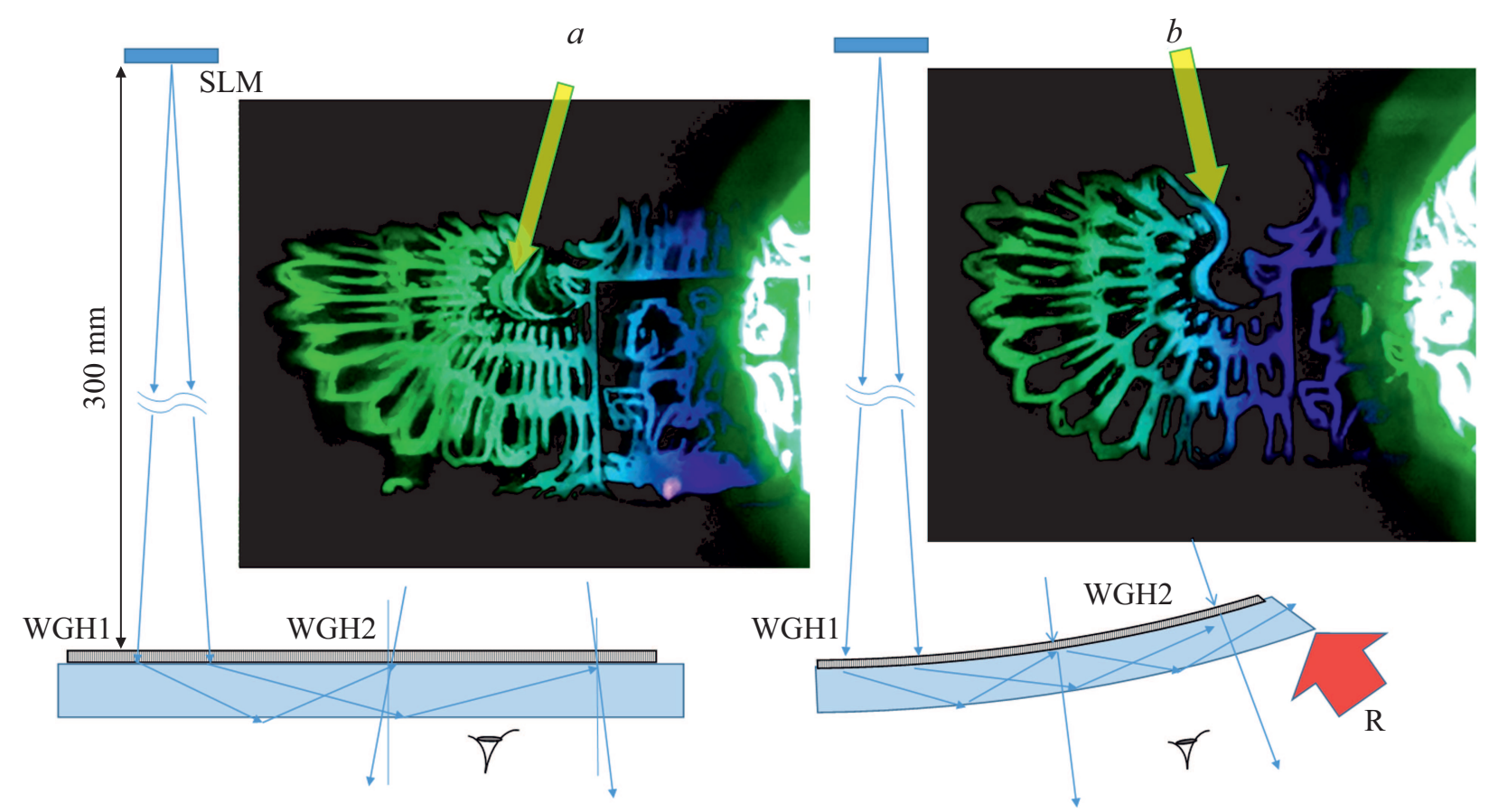

Рис. 9. Работа волноводного голографического перископа при настройке виртуального изображения не на бесконечность $(300 \mathrm{~mm})$. (a) Вид смещения (рассыпания) виртуального изображения - изображение при каждом отражении смещается относительно предыдущего, $(b)$ нет смещения виртуального изображения при изгибе волновода.

неизображающий перископ, синтезирующий большой зрачок и одновременно сильно ухудшающий световой КПД оптической системы HMD-дисплея. Поскольку для мультипликации зрачка приходится выводить из волновода гораздо больше лучей, чем нужно для конкретного положения зрителя, то световой КПД перископических голографических волноводов составляет единицы процентов и еще ухудшается при увеличении поля зрения. Применение брэгговских регистрирующих сред с управлением селективностью дифракции и углом Брэгга может значительно улучшить эффективность таких оптических схем, но сложность всего дисплея значительно возрастает и требует системы слежения за положением глаз зрителя.

Другим принципиальным ограничением в работе волноводных голографических перископов является „рассыпание“ изображения при формировании виртуального изображения не на бесконечности, а на конечном расстоянии от зрителя. Это становится очевидным, если рассмотреть формирование искажения неплоского волнового фронта при волноводной дифракции: в каждой точке возврата радиус неплоского волнового фронта увеличивается на оптическую длину пути до следующей точки возврата; таким образом, выходящий из волновода мультиплицированный волновой фронт формирует как по дальности, так и по углу разные локальные изображения. Для примера приведем фотографии фрагмента виртуального изображения при расстоянии до виртуального изображения $300 \mathrm{~mm}$ (рис. $8, a$ ): видно, что изображение, восстанавливаемое от соседних точек возврата, двоится. Скомпенсировать уход угла восстановления можно изгибом волновода в направлении „от зрителя“ (рис. 9, $b$ ) по радиусу, приблизительно равному расстоянию до виртуального изображения. Таким образом, на каждом отражении формируется смещенное по углу изображение; в нашем примере оптимальный прогиб волновода - составил $2.5 \mathrm{~mm}$, что при длине решетки $H$ в $40 \mathrm{~mm}$ приблизительно соответствует радиусу $R$, равному $320 \mathrm{~mm}\left(R=H^{2} / 2 \Delta\right)$, т. е. близко к расстоянию формирования виртуального изображения.

При использовании волноводных голографических перископических мультиплексоров зрачка большое значение приобретает качество волноводов. Дело в том, что при многократном увеличении площади взаимодействия световых пучков с волноводом также многократно возрастают и искажения волнового фронта этих пучков. Рассмотрим сначала влияние неплоскостности волновода. Допустим, что волновод имеет угол непараллельности границ $\delta$ в направлении, перпендикулярном направлению распространения. При каждом взаимодействии с поверхностью волновой фронт поворачивается на угол $2 \delta$, а для эффективного размножения зрачка нужно $N$ переотражений в волноводе, в результате пучок уходит от своего первоначального направления распространения на $2 N \delta$. При распространении света в волноводе с клиновидностью порядка доли градуса в конце волновода отклонение направления распространения лазерного луча от исходного доходит до десятков градусов, и в результате сформированное таким волноводом виртуальное изображение будет полностью 
разрушено. При выводе волноводного луча из волновода на дифракционной решетке угол в воздухе будет еще больше, например в случае вывода излучения из стеклянного волновода с рельефной решеткой, перенесенной на поверхность волновода при помощи фотополимера, при средней толщине фотополимера в $40 \mu \mathrm{m}$ по площади голограммы и вариациях толщины всего $10 \mu \mathrm{m}$ наблюдаются гигантские искажения в виртуальном изображении. В реальном волноводе неоднородность толщины приводит не только к отклонению луча, но и к модуляции угла вывода в направлении распространения, в результате на виртуальном изображении наблюдается целый комплекс искажений: локальное двоение или размытие, масштабные искажения, искажение перспективы и пр. Таким образом, требования к качеству волновода и, следовательно, к точности изготовления оптических деталей возрастает по мере увеличения степени мультиплицирования зрачка и уменьшения толщины волновода. В современных HMD-дисплеях толщина волновода может уменьшаться до 300 или $500 \mu \mathrm{m}$, и количество точек возврата на апертуре выходного элемента может достигать 20-30 по одному направлению, что приводит к сильному удорожанию производства волноводов. Отдельно надо отметить, что наблюдаемая, по крайней мере в намерениях разработчиков HMD и HUD, тенденция к увеличению размеров волноводных структур до десятков сантиметров потребует изготовление волноводов с количеством точек возврата при работе таких дисплеев до нескольких сотен; нетрудно подсчитать ужесточение требований к качеству волноводов. К тому же поглощение и рассеяние волноводных мод при росте размеров волноводных структур предъявит дополнительные требования к качеству полировки и однородности материалов волноводов.

\section{Заключение}

Проведенный анализ свойств и ограничений волноводных голограмм показывает ряд уникальных свойств оптических дисплеев, построенных на базе волноводных голографических перископов. Формирование больших выходных зрачков при исключительной компактности привели к созданию виртуальных дисплеев, отвечающих требованиям массового потребительского рынка, собственно рынок AR-дисплеев и стал формироваться именно с выходом из лабораторий HMD-дисплеев на базе волноводных голограмм. Трезвое оценивание положительных и отрицательных свойств волноводных голографических перископов очень полезно для понимания направления возможного развития такой быстро развивающейся области оптики, как устройства отображения виртуальной информации, в частности применение голографических перископических мультиплексоров возможно с традиционными голографическими линзами [9] или в любых оптических дисплейных системах, где большой зрачок необходим при сохранении компактности оптической системы, формирующей виртуальное изображение.

\section{Благодарности}

Авторы благодарят Исследовательский центр Самсунг в Москве за многолетнее плодотворное сотрудничество.

\section{Конфликт интересов}

Авторы заявляют, что у них нет конфликта интересов.

\section{Список литературы}

[1] Upatnieks J. //Appl. Opt. 1992. V. 31. N 8. P. 1048-1052. doi 10.1364/AO.31.001048

[2] Benton S.A., Birner S.M., Shirakura Putilin A.N., Morozov V.N., Huang Q., Caulfield H.J. // Opt. Engin. 1991. V. 30. N 10. P. 1615-1620. doi 10.1117/12.55969

[3] Benton S.A., Birner S.M., Shirakura A. // Proc. SPIE. 1990. V. 1212. P. 149-157. doi: $10.1117 / 12.17977$

[4] Nam Kim et al. // Holographic Materials and Optical Systems / Ed. by Naydenova I., Intechopen, 2017. doi 10.5772/67297

[5] Suhara T., Nishihara H., Koyama J. // Opt. Commun. 1976. V. 19. I. 3. P. 353-358. doi 10.1016/0030-4018(76)90097-3

[6] Kress B.C. // Proc. SPIE. 2019. V. 11062. 110620J. doi $10.1117 / 12.2527680$

[7] Liu A., Zhang Y., Weng Y., Shen Z., Wang B. // IEEE Photonics J. 2018. V. 10. N 4. P. 1-10. doi 10.1109/JPHOT.2018.2856774

[8] Putilin A., Gustomiasov I. // Proc. SPIE. 2007. V. 6637. 66370 N. doi 10.1117/12.742913

[9] Shin B., Kim S., Druzhin V., et al. // Proc. SPIE. 2020. V. 11310. 113100F. doi 10.1117/12.254477 